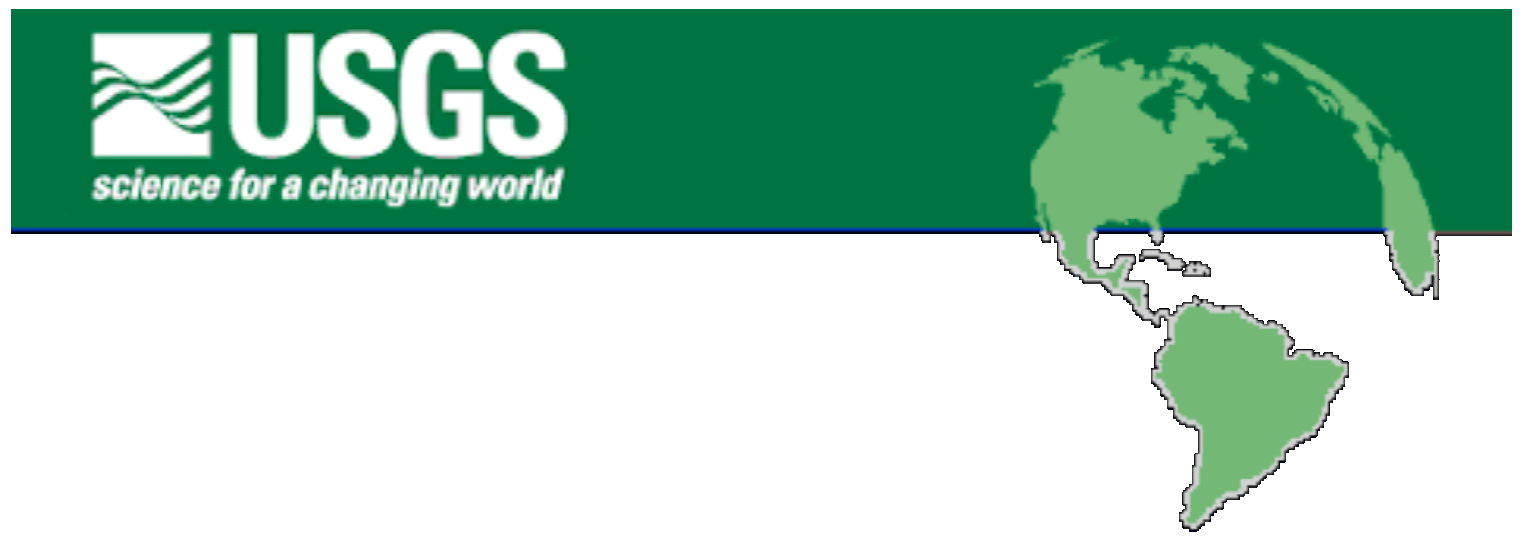

\title{
Preliminary Hydrodynamic
} Analysis of Landslide-Generated Waves in Tidal Inlet, Glacier Bay National Park, Alaska

By Eric L. Geist ${ }^{1}$, Matthias Jakob ${ }^{2}$, Gerald F. Wieczorek ${ }^{3}$, and Peter Dartnell ${ }^{1}$

Open-File Report 03-411

2003

This report is preliminary and has not been reviewed for conformity with U.S. Geological Survey editorial standards or with the North American Stratigraphic Code. Any use of trade, firm, or product names is for descriptive purposes only and does not imply endorsement by the U.S. Government.

\section{U.S. DEPARTMENT OF THE INTERIOR}

U.S. GEOLOGICAL SURVEY

\footnotetext{
${ }^{1}$ U.S. Geological Survey, Menlo Park, CA

${ }^{2}$ BGC Engineering Inc., Vancouver, BC, Canada

${ }^{3}$ U.S. Geological Survey, Reston, VA
} 


\section{Introduction}

A landslide block perched on the northern wall of Tidal Inlet, Glacier Bay

National Park (Figure 1), has the potential to generate large waves in Tidal Inlet and the western arm of Glacier Bay if it were to fail catastrophically. Landslide-generated waves are a particular concern for cruise ships transiting through Glacier Bay on a daily basis during the summer months. The objective of this study is to estimate the range of wave amplitudes and periods in the western arm of Glacier Bay from a catastrophic landslide in Tidal Inlet. This study draws upon preliminary findings of a field survey by Wieczorek et al. (2003), and evaluates the effects of variations in landslide source parameters on the wave characteristics.

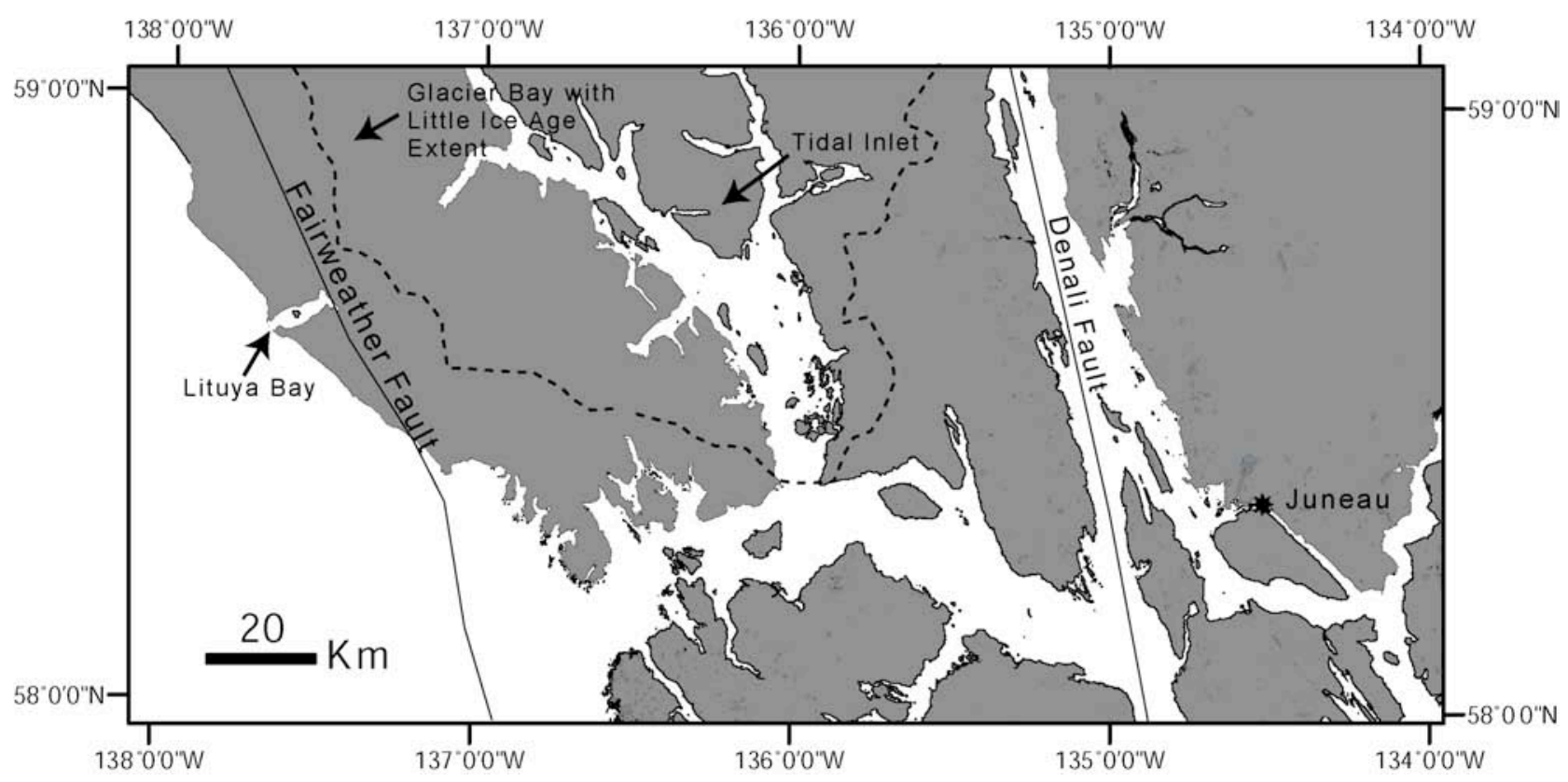




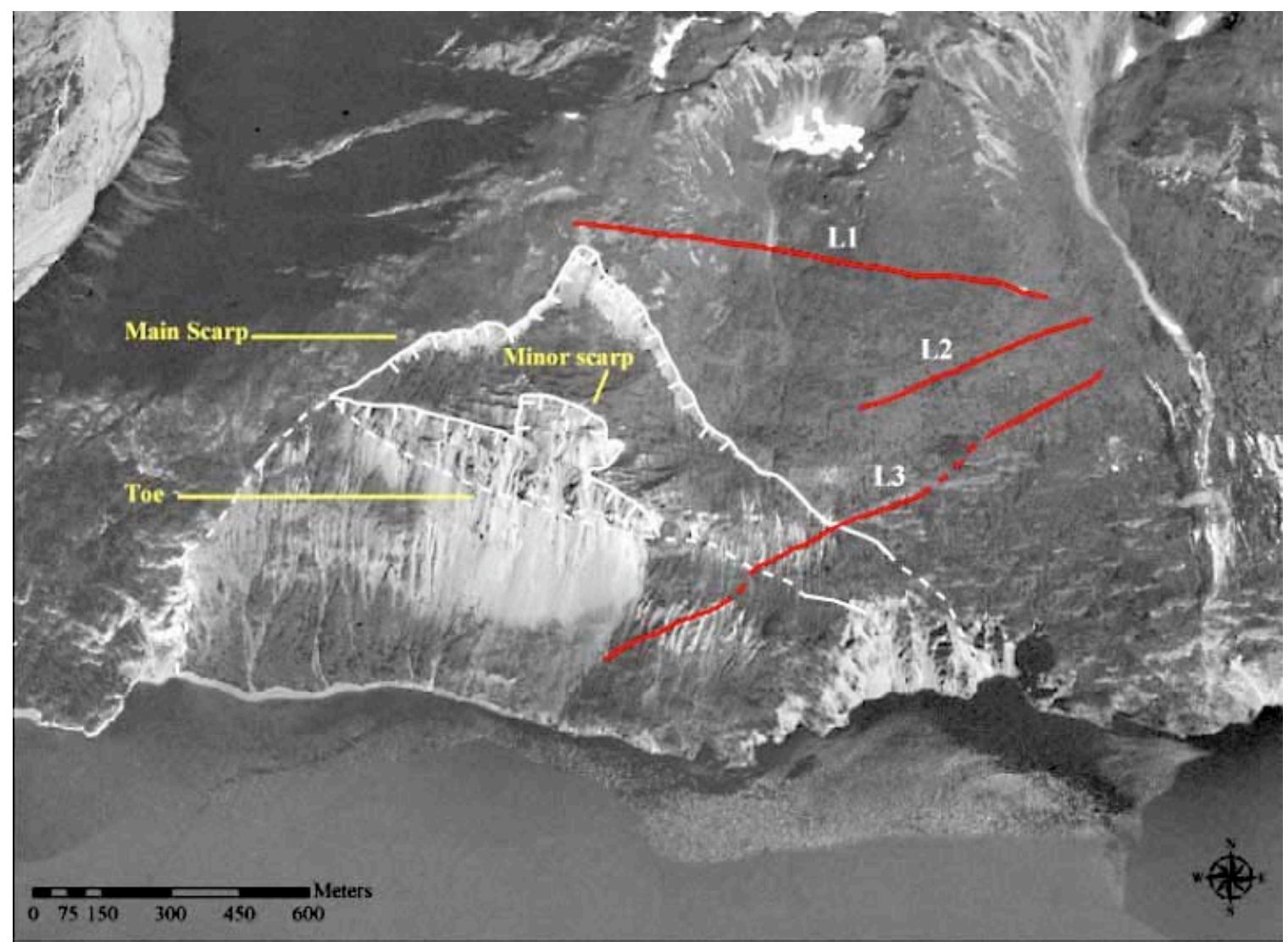

Figure 1: (top) Location map of Glacier Bay National Park, Alaska. Tidal Inlet shown along western arm of Glacier Bay. (bottom) Vertical aerial photograph (1996) showing approximate boundaries of the Tidal Inlet landslide mass and nearby lineaments (L1, L2, and L3). Figures from Wieczorek et al. (2003).

Modeling waves generated by sudden failure of landslide blocks entering fjords presents several difficulties. First, an appropriate wave generation model linked to the geometric and kinematic parameters of the slide must be implemented. The slide-water impact involves turbulent and non-linear flow that can only be approximated by modeling. In addition, catastrophic slope failure into fjords can result in wave runup on the opposite shore, as was observed following the 1958 Lituya Bay (Figure 1) slide (Fritz et al., 2001; Mader and Gittings, 2002). Runup and backwash is strongly non-linear and involves a complex parameterization of overland flow. Finally, resonance of wave action in fjords can also be non-linear, depending on the aspect ratio of the fjord and the amplification at resonance. 
This paper begins with a review of analytic studies of resonance in narrow bays such as Tidal Inlet. Resonance occurs at discrete length scales and analytic expressions can help determine if the length-scale of slide-generated waves occurs near the natural resonance of Tidal Inlet. Using first-order models, estimates are made of wave height and runup on the opposite shore of Tidal Inlet. Numerical models are then implemented to calculate the wave dynamics specifically for Tidal Inlet. A slide-impact wave generation model is used to specify the initial conditions for the propagation model. The propagation model is based on detailed bathymetry and is used to calculate the wave history in the western arm of Glacier Bay. Finally, implications of these unique waves on cruise ships are discussed.

\section{Resonance of Tidal Inlet: Analytic Approach}

The geometry of Tidal Inlet is ideally suited to allow a determination of the modes of natural resonance using analytic expressions. Early work on harbor resonance using inviscid theory by Miles and Munk (1961) describe the "harbor paradox" as follows: As the width ( $2 a$ - see Figure 2) of an elongated harbor or bay decreases, wave amplification becomes greater and tends toward infinity as $a \square 0$. For real fluids, other effects such as friction at the harbor entrance and non-linearity become important for narrow widths (Rogers and Mei, 1978; Mei, 1989; Raichlen and Lee, 1992).

To determine resonance of long and narrow bays, Rogers and Mei (1978) employ the Boussinesq equations at a constant water depth $(h)$ that include the effects on nonlinearity and dispersion:

$$
\begin{aligned}
& \square_{t}+\square \cdot \mathbf{u}+\square \cdot(\square \mathbf{u})=0 \\
& \mathbf{u}_{t}+\square \square+\frac{1}{2} \square \mathbf{u}^{2}+\frac{1}{3} \square^{2} \square \square_{t t}=0
\end{aligned}
$$

where $\square$ is the water surface displacement, $\mathbf{u}$ is the depth-averaged horizontal velocity field, and the small parameter $\square$ is defined by $\square^{2}=\square^{2} h / g$ where $\square$ is frequency. The variables in Equation 1 have been non-dimensionalized with respect to characteristic length and time scales. A rectangular bay geometry is used with a width $2 a$ and length $L$ (Figure 2). 


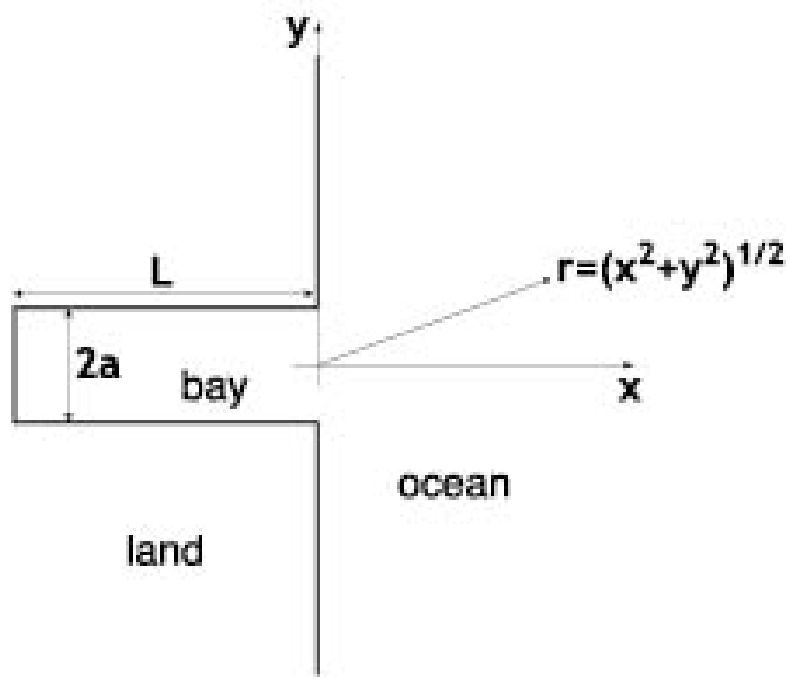

Figure 2: Geometry and coordinate system for a narrow bay.

The resonant wavenumbers $\left(k_{r}\right)$ are given by

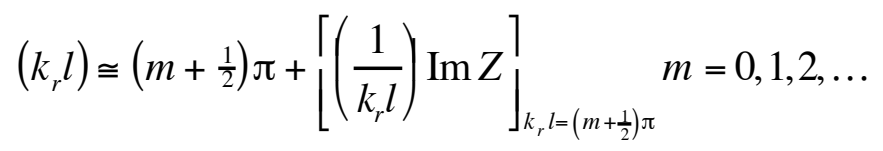

where $l$ is the non-dimensional length of the bay. The entrance impedance of the bay $(Z)$ is defined by Rogers and Mei (1978) as

$$
Z=k^{2} \square\left[\frac { 2 i } { \square } \operatorname { l n } \frac { \square } { \square } \frac { 2 \square } { \square e } \left[\frac{\square}{\square}\right.\right.
$$

where $2 \square$ is the non-dimensional bay width and $\square$ is Euler's constant. The aspect ratio of Tidal Inlet is approximately $\frac{2 \square}{l}=\frac{1}{7}$ such that the first two resonant modes are $\left(k_{r} l\right)_{1}=1.272$ and $\left(k_{r} l\right)_{2}=4.050$. These modes are slightly less than the $1 / 4$ and $3 / 4$ wavelength resonant modes predicted by a simple "quarter-wavelength resonator" (Raichlen and Lee, 1992). At resonant anti-nodes, there is no additional amplification of waves from resonance within the bay (i.e., unit response).

Outside the bay and far from the entrance, non-linear effects can be ignored. Rogers and Mei (1978) indicate that most bay and harbor resonant problems can be decoupled so that non-linear theory is used within the bay and linear theory is used in the ocean. The radiated wave from the bay, exclusive of incident and reflected waves outside the bay, is given by the following expression (Rogers and Mei, 1978): 


$$
\square_{\text {rad }}=i T k \square \sin (k l) H_{0}^{(1)}(k r)
$$

where $r^{2}=x^{2}+y^{2}>>\square x>0$ (Figure 2), $H_{0}^{(1)}(k r)$ is the Bessel function of the third kind (Hankel function) and

$$
T=A[\cos (k l) \square(i Z / k) \sin (k l)]^{\square 1}
$$

where $A$ is the non-dimensional amplitude of the incident wave. The wavefield from Equation (4) is shown in Figure 3.

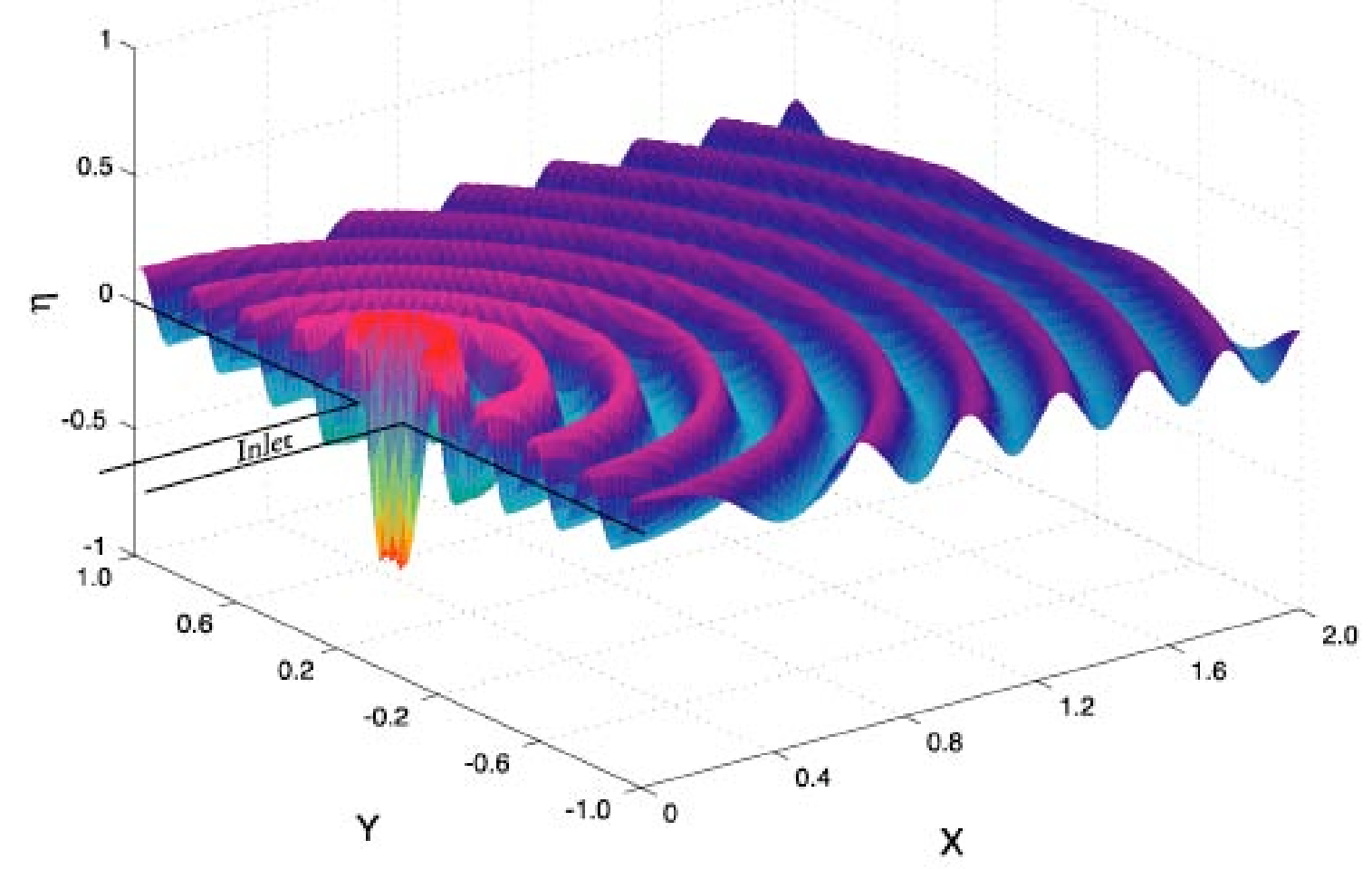

Figure 3: Radiant component of wavefield outside the bay from resonance involving monochromatic input. Axes in non-dimensional units.

Inside the bay, Rogers and Mei (1978) demonstrate that non-linear effects become increasingly important for longer bays. They compare experimental and theoretical results for three cases: $2 \square / l=0.275,0.0799,0.0467$. They note that for the shortest bay, linear theory is adequate to predict the effects of resonance and that entrance loss from friction may be a more important factor. For the longer bays, non-linearity becomes 
more important. Kowalik (2001) indicates that for transient waves associated with tsunamis, the effects of non-linearity dissipate shorter period waves and tend to preserve the long-period component of the spectra. When considering the effects of resonance on transient waves, Kowalik (2001) also notes that resonant amplification also depends on the duration of the wave train. Short wavetrains, relative to bay length, will not last long enough to set up resonance. Resonance in elongated coastal inlets may be more of a concern with longer-period waves from large seismogenic tsunamis (Carrier and Shaw, 1970; Henry and Murty, 1995).

\section{Near-Field Wave Estimates}

As indicated by Wieczorek et al. (2003), various analytic and empirical methods have been proposed to determine the waves generated by landslides at the point of impact. Because of the complex dynamics of subaerial landslides and the water waves they generate, most methods involve either a simplification of the physical processes that are involved or use regression analysis from flume studies or case histories. Analytic methods and scaling analysis often assume that the landslide can be approximated as a coherent mass entering the water. From this assumption, the landslide kinematics can be described using simple parameters such as landslide volume, velocity, and others. Because the fluid dynamics near the point of impact involves turbulent and non-linear behavior (e.g., Fritz et al., 2001; Mader and Gittings, 2002), some type of efficiency parameter is often implemented to account for fluid complexity near the source.

To determine the height of the leading elevation wave generated from a subaerial landslide, we use the method proposed by Huber and Hager (1997). Wieczorek et al. (2003) describe the parameters and underlying assumptions of this method. For the maximum volume $\left(10 \mathrm{Mm}^{3}\right)$ landslide into Tidal Inlet, the wave height in the center of the inlet is estimated to be $77 \mathrm{~m}$. We use this estimate to constrain our landslide impact model (described in the next section) to calculate the initial tsunami wavefield for farfield propagation. Other methods reviewed by Wieczorek et al. (2003) yield smaller estimates for initial wave height. 


\section{Numerical Model of Hydrodynamics}

In order to calculate the wave motion in Glacier Bay using realistic bathymetry, we use a numerical method to simulate wave propagation generated by a fast-moving sub-aerial landslide into Tidal Inlet. The initial tsunami wavefield is determined from a slide-impact model parameterized using the velocity, density, and effective dimension of the landslide. Wave propagation is modeled using the shallow-water wave equations, where the wavelength is considered to be significantly greater than the water depth.

\section{Source Model}

Whereas studies such as that of Huber and Hager (1997) yield information on the wave height from a landslide source, a source model needs to be employed that will specify the initial wavefield for simulating the propagation of these waves using realistic bathymetry. Wieczorek et al. (2003) indicate that a subaerial landslide would be moving at a high velocity $(67 \mathrm{~m} / \mathrm{s})$ when it reaches the water surface. This velocity is greater than the phase speed of long waves (or celerity) in the inlet, resulting in an impact Froude

number ( $F=v_{\text {slide }} / \sqrt{g h}$, where $h$ is water depth) of approximately 1.5. For comparison, the estimated velocity of the 1958 Lituya Bay slide is $110 \mathrm{~m} / \mathrm{s}$ with an impact Froude number of 3.18 (Fritz et al., 2001). Both the potential Tidal Inlet slide and the actual Lituya Bay slide have a high relative velocity (i.e., $F>1$ ), such that the displaced water generates an air cavity near the point of impact (Fritz et al., 2001; Mader and Gittings, 2002). The motion of the slide after impact is of secondary importance in generating waves. In contrast, for low relative velocity slides (i.e., $F<1$ ), such as subaerial slides that start near the water surface or submarine slides, the water is displaced during slide movement such that the time history of the slide is a critical parameter in determining wave height. In summary, for the potential Tidal Inlet slide, and, perhaps for most slides perched along the walls of fjords, a slide-impact generation mechanism, as indicated by Fritz et al. (2001) and Mader and Gittings (2002), is most appropriate.

We use the impact model of Ward and Asphaug $(2000,2002)$ developed for asteroid-generated tsunamis to define the initial conditions for wave propagation. This model is chosen because of the direct connection between impact kinematics and 
wavefield away from the source. In addition, this model is consistent with waves calculated using fully-three dimensional simulations of impacts (Ward and Asphaug, 2000). The initial wavefield from an impact is a parabolic cavity of maximum depth $D_{C}$ and inner and outer radii $R_{C}$ and $R_{D}$, respectively:

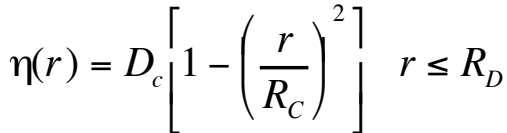

$$
\begin{aligned}
& \square(r)=0 \quad r>R_{D}
\end{aligned}
$$

As indicated by Ward and Asphaug $(2000,2002)$, if $R_{D}=\sqrt{2} R_{C}$, then the volume of water displaced from the cavity is preserved along the outer edge as a leading-elevation wave. The Schmidt-Holsapple (1982) scaling relation links the impactor kinematics (velocity, $V_{i}$; radius, $R_{i}$; and density, $\left.\square_{i}\right)$ to the cavity radius $\left(R_{C}\right)$ :

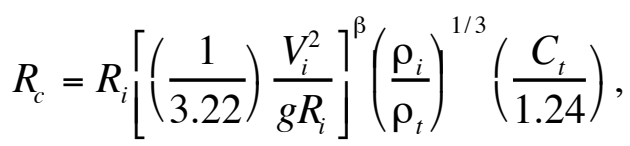

where $\square$ and $C_{t}$ are target properties $\left(\square=0.22\right.$ and $C_{t}=1.88$, see Ward and Asphaug, 2000 ) and $\square_{t}$ is the target density (in this case water, $\left.\square_{t}=1.0 \mathrm{gm} / \mathrm{cm}^{3}\right)$. Cavity depth $\left(D_{C}\right)$ is related to the cavity radius by the following expression:

$$
D_{C}=q R_{C}^{\square},
$$

where $\square=1 /(2 \square) \square 1$ and $q$ can be determined from the Schmidt-Holsapple relation (7). Ward and Asphaug (2000) indicate that the effect of these parameters is that deeper and narrower cavities are created by smaller diameter impactors travelling at the same velocity.

Because the dimensions of the potential Tidal Inlet slide are not radially symmetric and it is unknown as to how the shape of the slide will change during failure and disintegration, an effective impact radius is calculated from the height of the landslide generated wave using the method of Huber and Hager (1997). Using an impact velocity of $67 \mathrm{~m} / \mathrm{s}$ and an associated wave height of $77 \mathrm{~m}$, the effective impact radius is $115 \mathrm{~m}$ (Wieczorek et al., 2003);. Fritz et al. (2001) noted that the wave height for the Lituya Bay landslide is underestimated using the method of Huber and Hager (1997), primarily because landslides used to develop this relation were thinner than the Lituya Bay landslide (thickness $=92 \mathrm{~m}$, compared to $30 \mathrm{~m}$ for the potential Tidal Inlet 
landslide). It is therefore possible that the Huber and Hager (1997) method is more applicable for estimating wave heights in Tidal Inlet than for Lituya Bay.

To account for the non-equidimensional impactor shape of a subaerial landslide like the potential Tidal Inlet slide, we modify the impact shape function from the canonical parabolic cavity (Equation 6) to an elliptic paraboloid of the form:

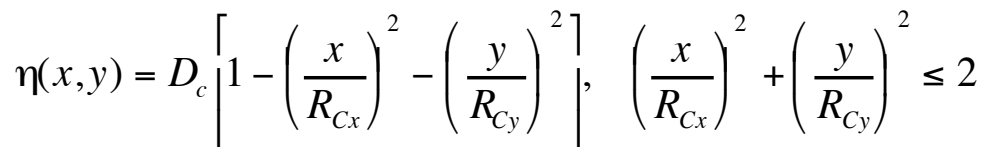

$$
\begin{aligned}
& \square(x, y)=0, \quad \frac{\mathrm{Z} x}{\square R_{C x} \mathrm{G}^{2}}+\frac{\mathrm{Q} y}{\square R_{C y}} \mathrm{I}^{2}>2
\end{aligned}
$$

The same cavity depth is used as for the parabolic cavity and the cavity radius in the direction of slide motion $\left(R_{C y}\right)$ is set equal to the parabolic cavity radius above. The cavity radius perpendicular to slide motion $\left(R_{C x}\right)$ is varied to accommodate different slide widths. Different source shape functions are shown in Figure 4.

(a)

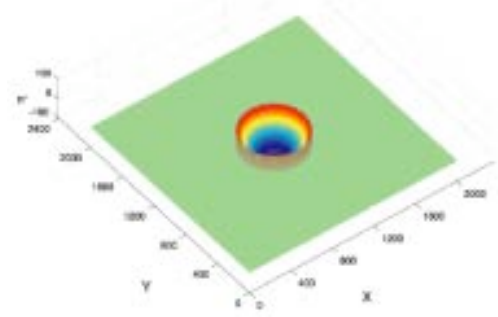

(b)

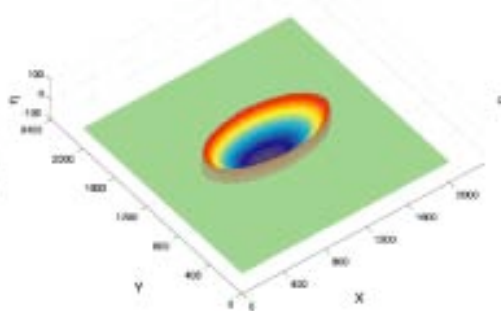

(c)

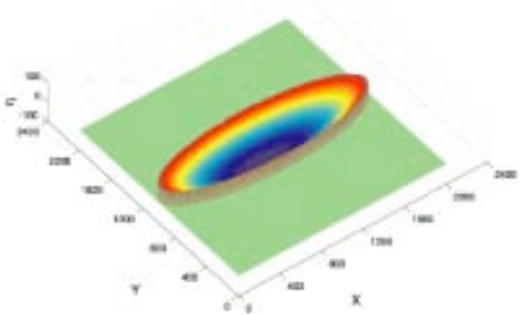

Figure 4: Source shape functions from the slide-impact model. (a) parabolic impact from an spherical impactor using the expressions in Ward and Asphaug (2000); (b) elliptic parabaloid impact from an oblate impactor with width equal to the average slide width described by Wieczorek et al. (2003); (c) elliptic parabaloid impact from an oblate impactor with width equal to the maximum slide width described by Wieczorek et al. (2003).

\section{Propagation Model}

With the initial wavefield specified from the modified slide-impact source model (Equation 9), wave propagation is calculated using a numerical approximation to the shallow water wave equations (e.g., Geist and Dmowska, 1999; Geist, 2002; Satake, 2002). A standard finite-difference method using a staggered grid $(\square x)$ is used in which 
the time step for the calculations $(\square t)$ is constrained by the Courant-Friedrichs-Lewy (CFL) stability criterion: $\square t \square \square x / \sqrt{2 g h}$. The bathymetry used in the calculations is derived from recently acquired multibeam data (Carlson et al., 2003) merged with older NOAA data and gridded at a $60 \mathrm{~m}$ spacing. The model domain is shown in Figure 5.

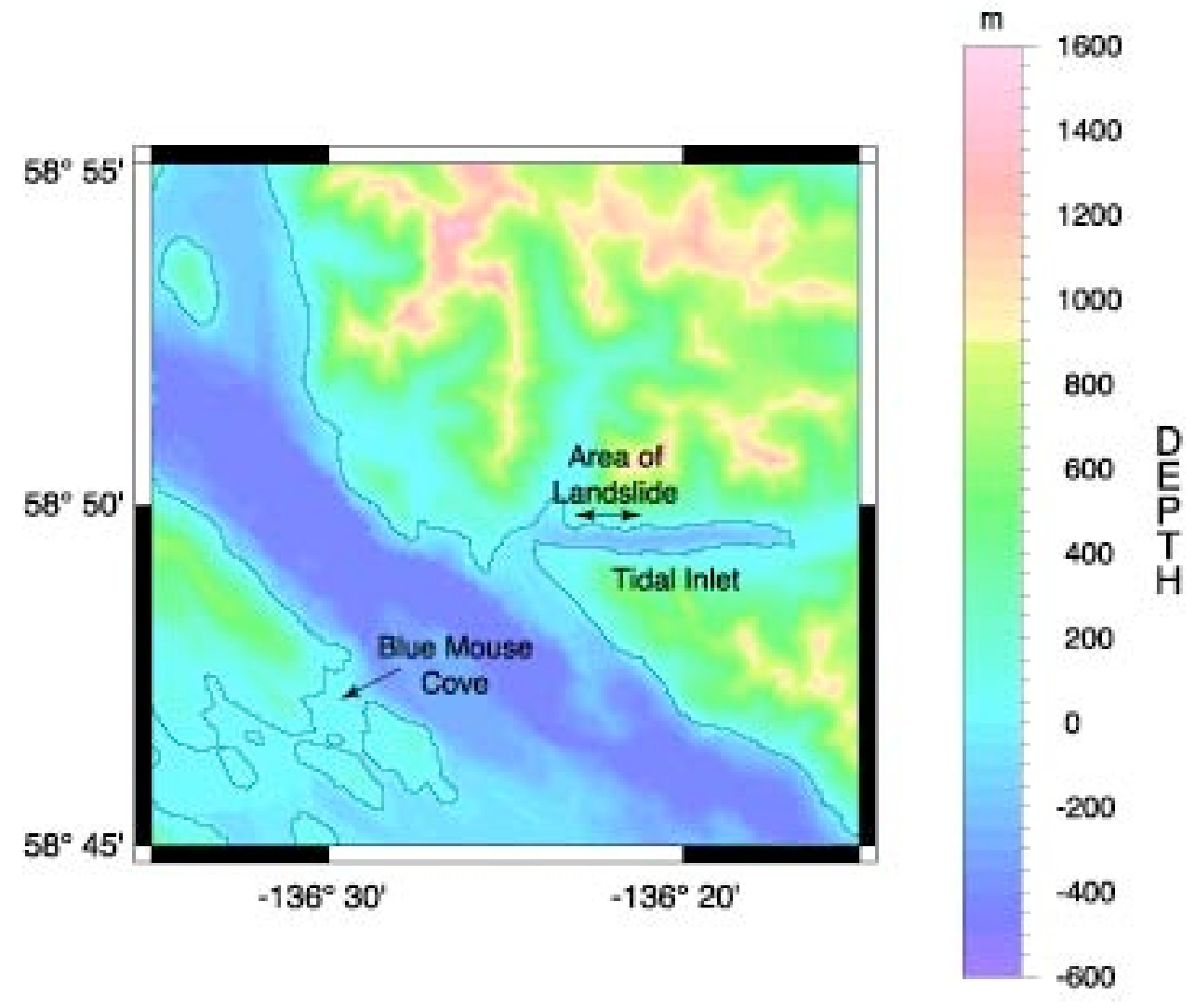

Figure 5: Model domain for wave propagation calculations and bathymetry of western arm of Glacier Bay and Tidal Inlet.

The time step used in all simulations is $0.5 \mathrm{~s}$ and the duration is up to 3 hours. At open boundaries, a radiation boundary condition is used (Reid and Bodine, 1968). At landocean boundaries, a total reflection boundary condition is used. For regions where there is significant wave runup (e.g., broadside from the source region), the reflection boundary condition may overestimate amplitudes of reflected waves that, with overland flow, would be dissipated by frictional forces. In addition to reflected and refracted waves propagating throughout the waterways, there also are coastal trapped waves that are strongest with gentle nearshore slopes (Carrier, 1995; Fujima et al., 2000). These waves can be approximately modeled with the method applied in this study. 
Using the dimensions of the potential Tidal Inlet slide described above, the small parameter $\square^{2}=O(0.1)$, indicating that waves may be affected by dispersion during propagation (Rogers and Mei, 1978), especially in the deeper parts of the waterways. Shuto (1991) and Murty and Kowalik (1993) demonstrate that physical dispersion can be implicitly modeled by numerical dispersion that results from finite-difference methods used in this study. They also indicate that this technique for modeling dispersion may, in fact, be preferable to explicit implementation of the Boussinesq equations (1) under certain conditions.

\section{Results}

The wave-history at any particular location in the study region can be characterized by the (a) first arrival of waves emanating from the source followed by (b) a complex wave train or coda resulting from reflections, scattering, and trapped waves. Outside Tidal Inlet, the first arrivals may include a direct phase, depending on the ray path to the target location, followed by simple reflection phases. The first waves have a longer period than waves in the coda and can be thought of as cylindrical waves emanating from the mouth of Tidal Inlet (Figure 3). Figure 6 shows eight snapshots of wave propagation from shortly after generation through the first hour. 

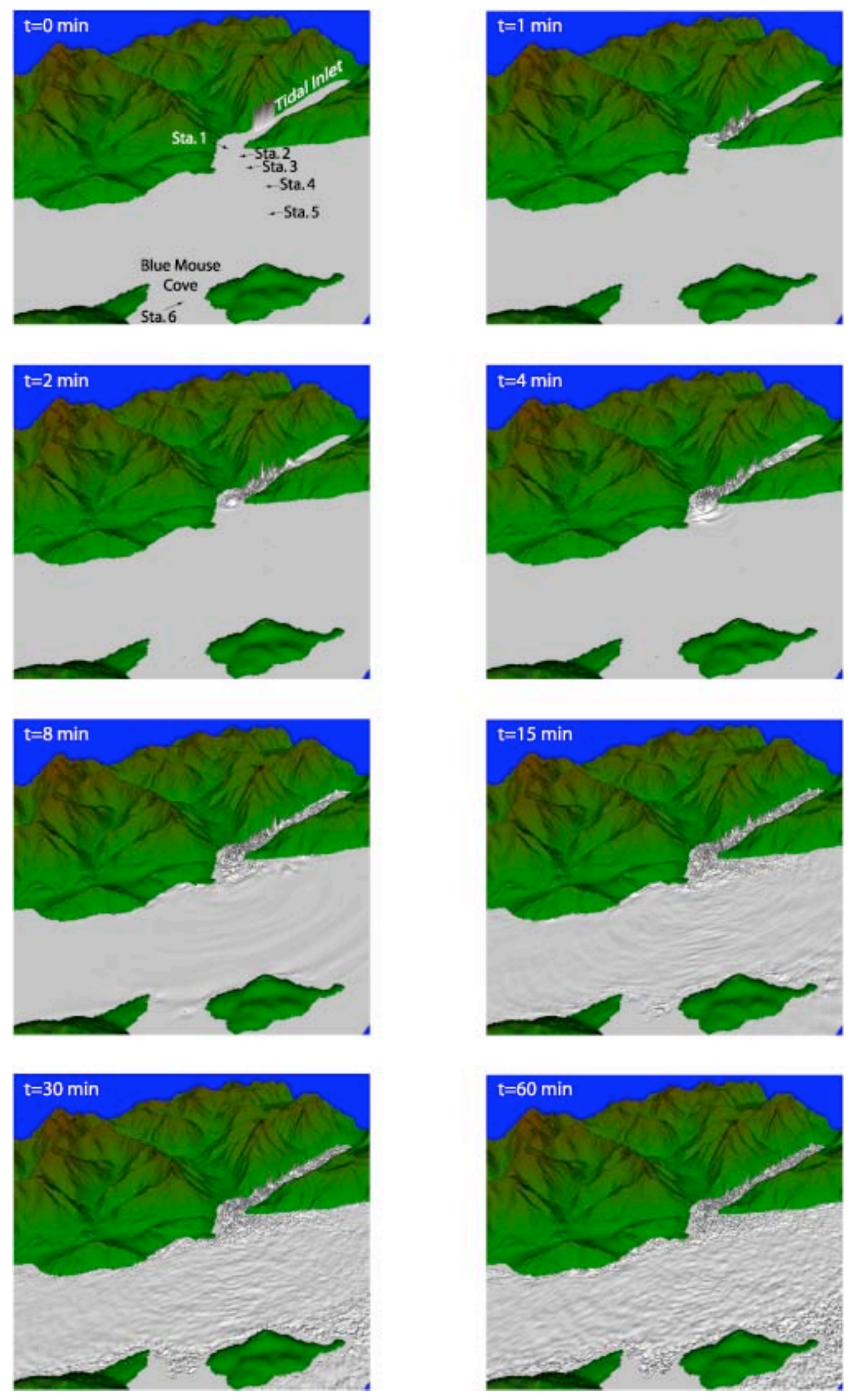
Figure 6: Eight snapshots of the tsunami propagation simulation. View to the northeast. Snapshot at $\mathrm{t}=\mathbf{0}$ min shows synthetic wave gauge station locations.

The waves reverberate within Tidal Inlet and eventually pass through the mouth and into the western arm of Glacier Bay as a series of cylindrical waves. As the waves pass into the deeper waters of Glacier Bay, the wavelength increases and the amplitude decreases according to Green's Law:

$$
\frac{\square_{1}}{\square_{0}}=\frac{G b_{0}}{\square b_{1}} \mathrm{~g}^{1 / 2} \frac{\mathrm{g} h_{0}}{\square h_{1}} \mathrm{~g}^{1 / 4}
$$

where $b_{1} / b_{0}$ represents the spreading of ray paths ( $b$ is the distance between rays) and $h_{1} / h_{0}$ represents the fractional change in depth (Satake, 2002). As the waves re-enter shallow water, the amplitude increases and the wavelength decreases. This is especially evident for the later times (Figure 6; $\mathrm{t}=30,60 \mathrm{~min}$.) where the shallow reaches of the waterways have higher amplitude and shorter period waves.

These characteristics can also be demonstrated by examining synthetic wave time history records or marigrams for several points in the model domain. Six synthetic wave gauges are positioned from the mouth of Tidal Inlet, across the western arm of Glacier Bay, and in Blue Mouse Cove (Figure 6; $\mathrm{t}=0 \mathrm{~min}$ ). Figure 7a shows marigrams for the first 10 minutes after the landslide enters Tidal Inlet.

(a)

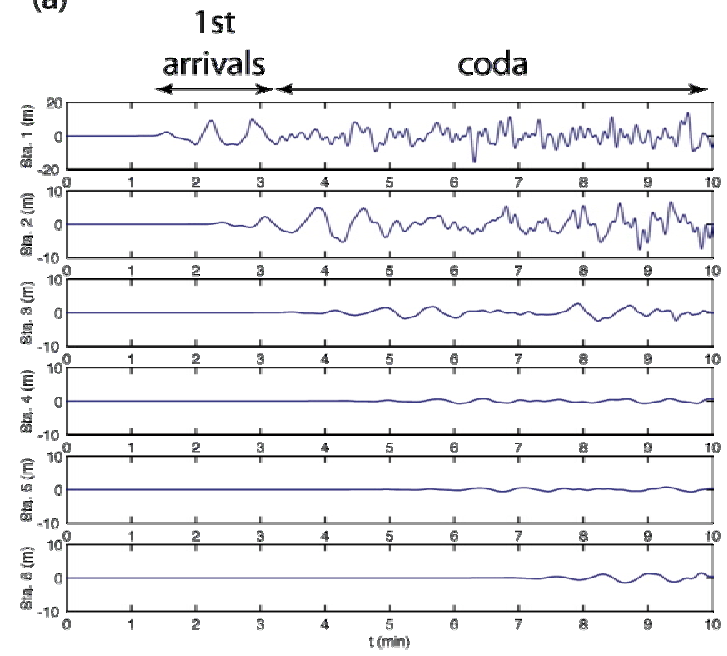

(b)

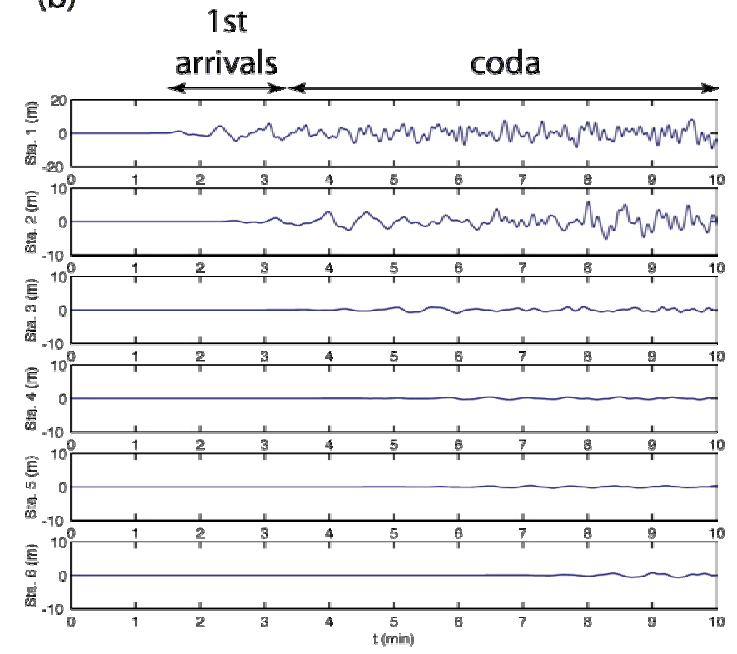

Figure 7: Synthetic marigrams for six station locations shown in Figure 5 ( $t=0$ min) for a duration of 10 minutes. Note that the vertical scale for Station 1 (top) is $\pm 20 \mathrm{~m}$, 
whereas for the other stations, the scale is $\pm 10 \mathrm{~m}$. (a) wave calculations for the maximum slide width $(1200 \mathrm{~m})$; (b) wave calculation for the average slide width (700 m).

A reduction in wave amplitude in the central part of Glacier Bay is evident (Stations 4 and 5), with a slight increase in first arrival amplitude in Blue Mouse Cove (Station 6). Also evident in the marigrams for Stations 1 and 2 is the longer-period response of the first arrival compared to the broadband coda that follows. The hydrodynamic simulation is re-computed for an average slide width of $700 \mathrm{~m}$ (Wieczorek et al., 2003). The synthetic marigrams are shown in Figure 7b. Most noticeable is an increase in short period waves in the first arrivals and coda for the smaller slide. In addition, the maximum wave amplitude appears to be slightly less for the smaller slide.

Figure 8 a shows the marigrams for a duration of 3 hours and the maximum slide width to illustrate decay characteristics at different locations.

(a)

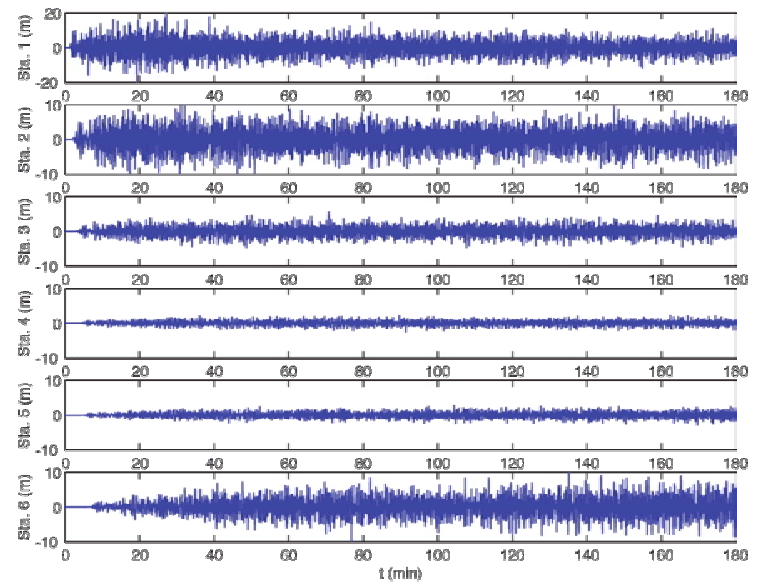

(b)

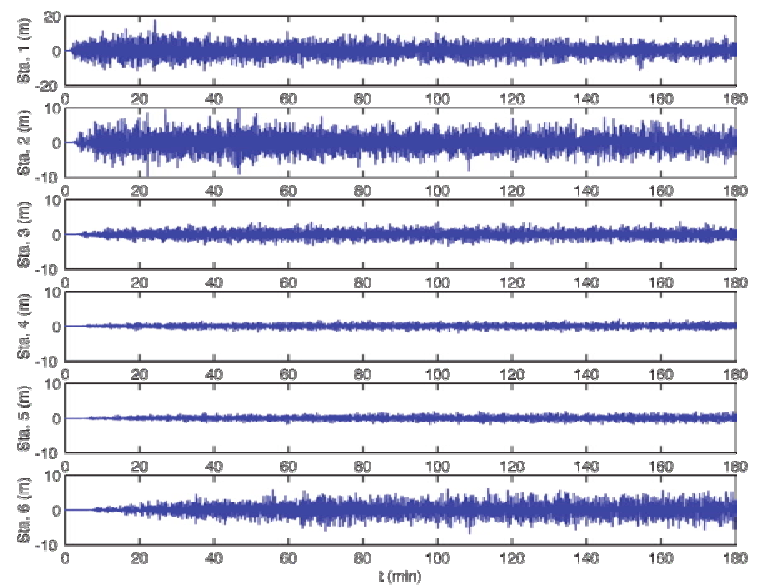

Figure 8: Same as Figure 7 for a duration of 3 hours.

A gradual decay in wave amplitude is evident for station 1, nearest the source. In contrast, for station 5 in Blue Mouse Cove, the wave amplitude gradually increases and persists for a long duration. The marigrams for the average slide width (Figure 7b) show similar station-location characteristics, with a reduction in the overall wave amplitude. These observations are consistent with the findings of Rabinovich (1997) who examines the spectra of tsunami waves recorded on tide gauge stations. In that study, it was 
evident that the wave histories were more dependent on the station response caused by the local bathymetry near the station than on the spectral characteristics of the source.

The long duration of waves generated in semi-enclosed bodies of water is also observed for tsunamis generated in marginal seas. Satake and Shimazaki (1988) demonstrate that the free oscillation of the Japan Sea from seismogenic tsunamis can persist for up to 48 hours. The duration of wave action in Glacier Bay from a landslidegenerated wave source in Tidal Inlet is more difficult to determine. Optimally, a remote observation system would be available with which to assess the wave activity in Glacier Bay after a major subaerial slide occurs. This could include land-based or airborne visual observations and/or telemetered wave-gauge recordings.

\section{Summary and Conclusions}

Numerical simulations of waves generated by a major subaerial slide in Tidal Inlet indicate that significant wave activity would occur in the western arm of Glacier Bay for more than several hours. A slide-impact source model, consistent with the findings of Fritz et al. (2001) and Mader and Gittings (2002) for waves generated by 1958 Lituya Bay slide, is used to specify the initial conditions for wave propagation in the Glacier Bay waterways. The kinematic and geometric parameters for the slide are taken from Wieczorek et al. (2003). Analytic studies of resonance in a narrow and elongated bay indicate that the first several modes of resonance are excited by much longer wave periods than are likely to be generated by a Tidal Inlet subaerial landslide. Wavetrains of long duration are caused by oscillations at the source that are characteristic

of impact-type generating mechanisms (Momoi, 1964; Ward and Asphaug, 2000). Also contributing to the long duration are cross channel-resonance and the site-specific response at locations outside the Inlet.

The maximum volume slide indicated by Wieczorek et al. (2003) generates very high waves (tens of meters in amplitude with possible $>100 \mathrm{~m}$ wave runup) near the source. It is likely that very high amplitude waves would persist throughout Tidal Inlet. Outside the Inlet, waves of significant amplitude (>10m) occur in shallow water regions, especially near the mouth of Tidal Inlet. In the deep waterways of the western arm of 
Glacier Bay, the wave amplitude decreases with distance according to Green's Law. A landslide with a lower volume generates waves with shorter periods throughout the first arrivals and coda of the wavetrain. Differences in wave characteristics among locations in Glacier Bay are primarily dependent on the local bathymetry--changes in slide parameters primarily influence the overall amplitude of waves. Because the duration of slide-generated waves is difficult to accurately predict, it is recommended that a remote observation system be used to assess when significant wave activity following a major subaerial slide has subsided.

The response of cruise ships in the region to these waves likely depends on which

part of the wavetrain the ships encounter. Near the mouth of Tidal Inlet, the amplitude of waves is greatest within approximately 40 minutes after the slide enters the water. Moreover, the first arrivals here and elsewhere in the vicinity of Tidal Inlet are likely to be long period waves (periods of up to 1 minute) and approximately unidirectional: i.e., can be characterized as cylindrical waves emanating from the mouth of Tidal Inlet. In contrast, the coda of the wavetrain is caused by multiple reflected, scattered, and trapped waves that are broadband and have a wide range of incidence angles. Further study is needed and would have to involve nautical engineers to determine the exact response of ships in the region to these waves.

\section{Acknowledgements}

EG, GW, and PD acknowledge the personal effort of Matthias Jakob toward the investigation of the Tidal Inlet landslide hazard. This report benefited from constructive technical reviews by Homa Lee and Robert Kayen.

\section{References}

Carlson, P.R., Hooge, P. N., Cochrane, G. R., Stevenson, A. J., Dartnell, P., and Stone, J. C., 2003, Multibeam bathymetry and selected perspective views of Glacier Bay, Alaska. USGS Water Resources Investigations Report 03-4141.

Carrier, G.F., 1995, On-shelf tsunami generation and coastal propagation, in Tsuchiya, Y., and Shuto, N., eds., Tsunami: Progress in Prediction, Disaster Prevention and 
Warning: Advances in Natural and Technological Hazards Research: Dordrecht, The Netherlands, Kluwer, p. 1-20.

Carrier, G.F., and Shaw, R.P., 1970, Respons of narrow-mouthed harbors, in Adams, W.M., ed., Tsunamis in the Pacific Ocean: Honolulu, East-West Center Press, p. 377-398.

Fritz, H.M., Hager, W.H., and Minor, H.E., 2001, Lituya Bay case: rockslide impact and wave run-up: Science of Tsunami Hazards, v. 19, p. 3-22.

Fujima, K., Dozono, R., and Shigemura, T., 2000, Generation and propagation of tsunami accompanying edge waves on a uniform shelf: Coastal Engineering Journal, v. 42, p. 211-236.

Geist, E.L., 2002, Complex earthquake rupture and local tsunamis: Journal of Geophysical Research, v. 107, no. B5, p. ESE 2-1 - ESE 2-15.

Geist, E.L., and Dmowska, R., 1999, Local tsunamis and distributed slip at the source: Pure and Applied Geophysics, v. 154, p. 485-512.

Henry, R.F., and Murty, T.S., 1995, Tsunami amplification due to resonance in Alberni Inlet, in Tsuchiya, Y., and Shuto, N., eds., Tsunami: Progress in Prediction, Disaster Prevention and Warning: Advances in Natural and Technological Hazards Research: Dordrecht, The Netherlands, Kluwer, p. 117-128.

Huber, A., and Hager, W.H., 1997, Forecasting impulse waves in reservoirs, in Dixneuvième Congrès des Grands Barrages, Florence, Commission Internationale des Grands Barrages, p. 993-1005.

Kowalik, Z., 2001, Basic relations between tsunamis calculation and their physics: Science of Tsunami Hazards, v. 19, p. 99-116.

Mader, C.L., and Gittings, M.L., 2002, Modling the 1958 Lituya Bay mega-tsunami, II: Science of Tsunami Hazards, v. 20, p. 241-250.

Mei, C.C., 1989, The Applied Dynamics of Ocean Surface Waves: Advanced Series on Ocean Engieering: Singapore, World Scientific, v. 1, 740 p.

Miles, J., and Munk, W., 1961, Harbor paradox: Journal of the Waterways and Harbors Division, A.C.E., v. 87, p. 111-130.

Momoi, T., 1964, Tsunami in the vicinity of a wave origin [I]: Bulletin of the Earthquake Research Institute, v. 42, p. 133-146. 
Murty, T.S., and Kowalik, Z., 1993, Use of Boussinesq versus shallow water equations in tsunami calculations: Marine Geodesy, v. 16, p. 149-151.

Rabinovich, A.B., 1997, Spectral analysis of tsunami waves: Separation of source and topography effects: Journal of Geophysical Research, v. 102, p. 12,663-12,676.

Raichlen, F., and Lee, J.J., 1992, Oscillation of bays, harbors, and lakes, in Herbich, J.B., ed., Handbook of Coastal and Ocean Engineering: Houston, Texas, Gulf Publishing Company, p. 1073-1113.

Reid, R.O., and Bodine, B.R., 1968, Numerical model for storm surges in Galveston Bay: Journal of the Waterways and Harbors Division, A.C.E., v. 94, p. 33-57.

Rogers, S.R., and Mei, C.C., 1978, Nonlinear resonant excitation of a long and narrow bay: Journal of Fluid Mechanics, v. 88, p. 161-180.

Satake, K., 2002, Tsunamis, in Lee, W.H.K., Kanamori, H., Jennings, P.C., and Kisslinger, C., eds., International Handbook of Earthquake and Engineering Seismology, International Association of Seismology and Physics of the Earth's Interior, Part A, 932 pp.

Satake, K., and Shimazaki, K., 1988, Free oscillation of the Japan Sea excited by earthquakes--I. Observation and wave-theoretical approach: Geophysical Journal, V. 93, p. 451-456.

Schmidt, R.M., and Holsapple, K.A., 1982, Estimates of crater size for large-body impacts: Gravitational scaling results, in Silver, L.T., and Schultz, P.H., eds., Geological implications of impacts of large asteroids and comets on the Earth: Geological Society of America Special Paper 190: Boulder, CO, p. 93-102.

Shuto, N., 1991, Numerical simulation of tsunamis--Its present and near future: Natural Hazards, v. 4, p. 171-191.

Ward, S.N., and Asphaug, E., 2000, Asteroid impact tsunami: a probabilistic hazard assessment: Icarus, v. 145, p. 64-78.

Ward, S.N., and Asphaug, E., 2002, Impact tsunami--Eltanin: Deep-Sea Research II, v. 49, p. 1073-1079.

Wieczorek, G.F., Jakob, M., Motyka, R.J., Zirnheld, S.L., and Craw, P., 2003, Preliminary landslide-induced wave hazard assessment: Tidal Inlet, Glacier Bay National Park, Alaska: U.S. Geological Survey Open-File Report 03-100. 